\title{
Descrição sonora da língua pomerana
}

\author{
Sound Description of the Pomeranian Language \\ Shirlei Conceição Barth Schaeffer \\ Alexsandro Rodrigues Meireles \\ Universidade Federal do Espírito Santo - Vitória - Espírito Santo - Brasil
}

\begin{abstract}
Resumo: Este artigo focaliza a descrição do sistema sonoro da língua de imigração pomerana, ainda muito falada em alguns municípios do estado do Espírito Santo, em Rondônia e no sul do Brasil, através do método da fonêmica, desenvolvido por Pike (1947). Para isso, quatro sujeitos (três bilíngues em pomerano e português e uma monolíngue em pomerano) foram entrevistados e lhes foi apresentada uma lista de seiscentos itens lexicais, dos quais pudemos identificar os fones consonantais e vocálicos, formar pares mínimos para construir a tabela de fonemas consonantais e vocálicos, visualizar processos fonológicos e, por fim, descrever a estrutura silábica do pomerano.
\end{abstract}

Palavras-chave: Pomerano; Fonética; Fonêmica; Sílaba

\begin{abstract}
This paper describes the sound system of the Pomeranian language, which is still spoken in some regions of Brazil. This description was based on the phonemics' method, developed by Pike (1947). In order to do so, four subjects (three bilinguals (Portuguese and Pomeranian) and one monolingual (Pomeranian)) were interviewed and then they were presented to a list of six hundred lexical items, of which we could identify consonant and vowel phones, gather minimal pairs to build the phonemic table of consonants and vowels, observe some phonological processes and, finally, describe the syllabic structure of Pomeranian.
\end{abstract}

Keywords: Pomeranian language; Phonetics; Phonemics; Syllable

\section{Introdução}

Apesar de o português ser a língua oficial do Brasil, algumas pessoas não o utilizam em alguns municípios capixabas, uma vez que se comunicam em línguas de imigração como o pomerano, herança linguística deixada pelos imigrantes provenientes da Antiga Pomerânia que vieram para o Espírito Santo a partir do século XIX.

O estado capixaba, durante o século XIX, recebeu imigrantes de diversas regiões da Europa por necessitar de mão de obra para a agricultura cafeeira, após a abolição da escravatura. Assim, imigrantes de países como Itália, Alemanha, Espanha, Portugal, Polônia, Holanda, Suíça, Áustria, França e outros chegaram ao estado em busca de uma vida nova, uma vez que a maioria das pessoas fugia do caos europeu provocado pelas transformações políticas e sociais, como as lutas pela unificação da Alemanha, a guerra francoprussiana e o crescimento do capitalismo industrial (SALAMONI, 2001). Dentre os imigrantes alemães, estavam os pomeranos, os quais vinham da Pomerânia, extinta após a derrota da Alemanha na Segunda Guerra Mundial, que situava-se nas costas do mar Báltico entre a atual Alemanha e Polônia.

A imigração pomerana inicia-se no Espírito Santo em julho de 1859 e cessa em 1870, ano em que as maiores levas de imigrantes fixam residência no estado. Estima-se que 30 mil pomeranos imigraram para o Brasil. Porém, outra parte de pomeranos imigrou para os Estados Unidos e para a Austrália, cerca de 331.400, aproximadamente, entre 1830 e 1900. Apesar de ser um número muito maior do que os que imigraram para o Brasil, não há registro de falantes de pomerano nos países supracitados. Somente aqui no Brasil a língua pomerana continuou a ser falada.

Atualmente, essa língua de imigração é falada pelos descendentes em comunidades do Espírito Santo, Minas Gerais, Rondônia, Santa Catarina e Rio Grande do Sul (TRESSMANN, 2005, p. 78). No Espírito Santo, os descendentes de pomeranos estão distribuídos por quinze municípios: 
a) Kulland (terra fria) - Domingos Martins, Santa Leopoldina, Santa Maria de Jetibá, Santa Teresa;

b) Warmland (terra quente) - Afonso Cláudio, Itarana, Laranja da Terra, Itaguaçu, Baixo Guandu;

c) Nord (norte) - Colatina, Pancas, São Gabriel da Palha, Nova Venécia, Barra de São Francisco e Vila Pavão (TRESSMANN, 2005, p. 66).

Estima-se que no Espírito Santo haja, em média, 120 mil descendentes de imigrantes pomeranos e, no Brasil, em torno de 300 mil indivíduos (TRESSMANN, 2008, p. 03).

\section{Classificação da Língua Pomerana}

Segundo Tressman (2005, p. 78), a língua pomerana pertence à família Germânica Ocidental, da subfamília Baixo Saxão (Oriental), a qual predomina na Pomerânia a partir de 1400. Assim, segundo o autor (2005), o pomerano, o saxão antigo, o anglo-saxão, o neerlandês, o sueco, o inglês, o alto alemão antigo e o alemão são línguas que apresentam um parentesco sistemático, pois todas essas línguas descendem do Germânico, língua extinta atualmente. Essas línguas germânicas junto com línguas românicas e eslavas pertencem ao tronco linguístico Indo-Europeu. A partir daí, há ramificações ou subfamílias. Sendo assim, o pomerano, o neerlandês e o inglês pertencem ao Saxão Antigo que originou subfamílias linguísticas. Dessa forma, o pomerano é uma língua baixo-saxônica, isto é, uma língua saxônica das terras baixas do Mar Báltico, na Europa. Já o inglês, por exemplo, é uma língua Anglo-Saxônica, por isso revela semelhanças com o pomerano. Por outro lado, o alemão pertence ao Alto-Alemão Antigo, isto é, das regiões altas da Alemanha e da Suíça, o qual se originou do Gótico, portanto pertence a uma família diferente da do pomerano, apesar de as duas línguas apresentarem muitas similaridades (TRESSMANN, 2008, p. 05).

O Pomerano passou a ser considerado como uma língua moribunda na Europa após a II Guerra Mundial e, aos poucos, foi deixada de lado pelos nativos já que era uma língua sem prestígio social e o alemão, a língua prestigiada. Por isso, muitas famílias deixaram de falar o pomerano e de ensiná-lo aos seus filhos, fato que contribuiu para a extinção dessa língua na Europa.

\subsection{Uso da língua}

Segundo Tressman (2005, p. 60-61), a partir de 1530, com a Reforma Luterana, a língua alemã passa a ser ensinada nas escolas e exigida em ambientes escolares, igrejas e repartições públicas, mas o pomerano continua a ser falado cotidianamente em ambientes informais com parentes e conhecidos. Situação semelhante ocorre atualmente com os descendentes de pomeranos, uma vez que usam essa língua de imigração no dia a dia com parentes, amigos e vizinhos, mas a língua portuguesa é exigida em situações formais.

O uso crescente do português entre os descendentes de pomeranos ocorreu na época da Campanha de Nacionalização, criada pelo governo de Getúlio Vargas entre 1938 a 1945, o que resultou em repressão ao uso da língua alemã e pomerana bem como publicações e ensino das mesmas. Além disso, nenhuma outra língua, exceto o português, poderia ser falada em público. Instituições e associações comunitárias e culturais foram fechadas, membros e pastores das igrejas luteranas foram perseguidos e propriedades destruídas. Enfim, um período que marcou a intolerância à diversidade linguística e opressão aos tantos imigrantes que viviam no país.

No Espírito Santo, o uso da língua portuguesa entre os mais jovens é crescente. Muitos pais alegam falar mais em português com os filhos para que não sofram preconceitos e humilhações. Segundo Bahia (2006, p. 73), para os pais que almejam a permanência dos filhos junto à lavoura, a escola é vista como meio para ensinar questões e situações formais com as quais eles irão lidar. Como a maioria das famílias descendentes de pomeranos vive em propriedades rurais por meio da agricultura familiar, a falta de um membro da família é muito sentida no trabalho cotidiano, por isso muitos jovens evadem da escola completando, no máximo, todo o ensino fundamental.

Por mais de um século, o pomerano mantém sua vitalidade no país sendo falado pelos seus descendentes. Em contrapartida, há poucos estudos descritivos sobre essa língua de imigração, a qual, até pouco tempo, era ágrafa e passa a ter uma ortografia a partir de 2006, proposta por Tressmann, ao lançar o "Dicionário Enciclopédico: Pomerano e Português" (Pomerisch Portugijsisch Wöirbauk) que contém, em média, 16 mil verbetes com informações gramaticais, etnográficas, históricas, geográficas e etimológicas. Além disso, o autor cita possíveis fonemas da língua com alguns exemplos e a respectiva forma ortográfica. Porém, essa breve descrição fonológica não contempla, de forma precisa, a complexidade do sistema sonoro do pomerano. Por isso, surge o interesse em descrever com mais detalhes a organização sonora dessa língua de imigração.

Dentre as pesquisas realizadas sobre o pomerano destacam-se: 1) a tese desenvolvida por Tressmann (2005) que apresenta um estudo etnolinguístico da comunidade pomerana explicitando a trajetória histórica da imigração bem como informações interessantes sobre o lugar de origem desse povo e aspectos culturais que ainda são preservados nas comunidades formadas por descendentes de pomeranos; 2) os trabalhos de Bandeira (2010) e Zimmer, Bandeira e Blank (2009) que fazem 
medidas acústicas do VOT (Voice Onset Time) das plosivas surdas do pomerano entre os descendentes de pomeranos de Arroio do Padre, Rio Grande do Sul; e, por fim, 3) o trabalho de Schaeffer e Meireles (2011) que também analisam o VOT das plosivas surdas e sonoras em início de palavra diante da vogal baixa central [a] entre falantes de pomerano capixabas com idade entre 15 a 25 anos de idade.

Trabalhos relacionados à influência do pomerano na língua portuguesa foram desenvolvidos por Benincá (2008) que analisou, no corpus oral, a troca de fonemas sonoros por surdos, a troca do ponto de articulação e a variação da estrutura silábica. Além disso, na escrita, teceu análises sobre desacordo entre fonema e letra, influências da língua oral, a troca de fonemas, hipercorreção, vocábulo fonológico e vocábulo formal e estrutura da sílaba entre alunos da $5^{\text {a }}$ série que possuem o pomerano como língua materna. Já Haese (2009) verificou processos de formação e redução de ditongo e a estrutura silábica entre descendentes de pomeranos do ensino fundamental. Por fim, Schaeffer (2010) categorizou as principais marcas da oralidade na escrita de alunos descendentes de pomerano de todo o ensino fundamental.

\section{Metodologia para descrição}

Para a descrição fonética e fonológica da língua de imigração pomerana, adotamos o modelo fonêmico de Pike (1947), de cunho estruturalista norte-americano. A escolha de uma metodologia estruturalista, em meio a tantos modelos modernos de análise fonológica, visa a alcançar uma descrição básica dos sons que constituem a língua em questão, visto que não há nenhuma descrição detalhada da mesma. Sendo assim, é um primeiro passo para descrever o pomerano. Uma vez identificados os fenômenos mais interessantes para a reflexão fonológica, o trabalho poderá ser ampliado com análises mais complexas.

O modelo fonêmico apresenta procedimentos metodológicos adequados para a análise de qualquer língua, pois assume que as estruturas das línguas são uniformes. Além disso, é possível converter a linguagem oral em código escrito, no caso de línguas ágrafas (PIKE, 1947). Os procedimentos fonêmicos estão baseados em algumas premissas que são características universais subjacentes das línguas. As quatro principais premissas são:

a) "Os sons tendem a ser modificados pelos seus ambientes". Sendo assim, a variação de um som pode ser causada pelos diferentes movimentos articulatórios, pelos sons vizinhos, pelas sílabas que podem ser acentuadas ou não, longas ou curtas, altas ou baixas e pelas bordas de variados tipos de unidades fonológicas ou gramaticais. b) "Os sistemas sonoros têm uma tendência a uma simetria fonética", por exemplo, as consoantes oclusivas surdas e suas respectivas sonoras. O sistema sonoro do português brasileiro pode ser considerado simétrico, pois possui vogais anteriores e posteriores na mesma proporção e a maioria das consoantes sonoras possuem suas contrapartes surdas.

c) "Os sons tendem a flutuar", ou seja, em uma língua hipotética o falante pode pronunciar uma oclusiva com ou sem aspiração sem ter valor distintivo, ou ainda, ora pronunciar uma oclusiva surda, ora uma sonora sem mudança de significado.

d) "Sequências de sons característicos exercem pressão estrutural na interpretação fonêmica de segmentos suspeitos ou sequências de segmentos suspeitos". Isso significa que, muitas vezes, o pesquisador pode ficar em dúvida ao classificar determinados segmentos. $\mathrm{O}$ [i] e o [u] não silábicos, por exemplo, podem ser identificados como consoantes ([j], [w]) ou como vogais. O que definirá essa interpretação baseia-se na observação da maneira em que esses segmentos ocorrem, incluindo a sequência de outros segmentos e os ambientes específicos. Sendo assim, Pike (1947) declara que em cada língua existem dois grupos principais de sons que possuem nitidamente diferentes distribuições: as vogais constituem o grupo que é frequentemente silábico, ou seja, ocupa o núcleo da sílaba e as consoantes formam um outro grupo que, frequentemente, funcionam como não silábicos.

De acordo com a metodologia adotada, o corpus da pesquisa foi constituído por uma lista de palavras isoladas e por pequenas frases com 600 itens, baseada nas listas de palavras para descrição de línguas indígenas. Assim, a lista foi baseada na Lista Diagnóstica léxico-estatística de Morris Swadesh para levantamentos e comparações de línguas indígenas, no Formulário do vocabulário-padrão para estudos comparativos preliminares nas línguas indígenas brasileiras do Museu Nacional do Rio de Janeiro e na Lista léxico-estatística proposta por índios segundo Alcionílio B. A. Silva. Além disso, acrescentamos e substituímos palavras do cotidiano dos descendentes de pomerano a fim de facilitar a compreensão.

Após a coleta e a análise dos dados, percebemos que a lista anterior era insuficiente para a montagem dos pares mínimos. Então, uma nova lista de 190 palavras foi criada e houve uma nova coleta com a informante bilíngue FLR e com a monolíngue FRF. Essa lista foi baseada no dicionário de pomerano e português de Tressmann (2006).

Os dados foram gravados na casa da pesquisadora, uma vez que um estúdio específico era distante e os sujeitos só tinham tempo para realizar as gravações à noite 
ou em finais de semana, já que precisavam trabalhar na agricultura durante o dia. As gravações foram realizadas com um gravador Handy Vídeo Recorder Q3, da ZOOM, versão 1.10 e os dados amostrados em PCM 44.1 kHz 16 bits. Antes de iniciar a gravação, o informante recebeu explicações de como seria a gravação. A sessão iniciavase pela entrevista de sondagem seguida da lista de palavras de 600 itens em que a pesquisadora perguntava "Como fala em pomerano?" e o informante respondia. Quando ele ficava em dúvida em alguma palavra, recebia explicações em português do significado da mesma.

O procedimento com a falante monolíngue foi diferenciado: as palavras foram previamente selecionadas para confirmar os pares mínimos da pesquisa em questão e eram apresentadas em forma de figuras para facilitar a compreensão da falante.

Os dados obtidos foram transcritos foneticamente, baseados no Alfabeto Fonético Internacional e transcritos com fonte SILDoulosIPA em uma planilha Excel para facilitar a comparação entre os falantes. A transcrição foi auditiva e acústica simultaneamente, através do software Praat em que os dados também foram etiquetados e separados por fones, já que o espectrograma facilita essa separação. A iniciativa de fazer uma análise auditiva e acústica baseou-se na facilidade de identificar os sons pelas suas características acústicas e de confirmá-los pela audição. Após a transcrição, os fones foram separados em uma tabela fonética, pares mínimos procurados para identificar os fonemas, as regras de alofonia apresentadas e, por fim, os fonemas foram agrupados em uma tabela fonêmica. Por fim, descrevemos a estrutura silábica dessa língua de imigração.

\section{Sistema consonantal do pomerano}

A língua de imigração pomerana é constituída por 29 fones consonantais, os quais podem ser classificados, articulatoriamente, quanto ao ponto de articulação (bilabial, labiodental, alveolar, pós-alveolar, palatal, velar e glotal); quanto ao modo de articulação que define consoantes oclusivas, fricativas, nasais, tepes, aproximantes e laterais; finalmente, quanto ao estado da glote definindo fones surdos e sonoros. Na tabela abaixo estão todos os fones consonantais do pomerano identificados com sua respectiva classificação articulatória e exemplos com tradução em português para cada segmento.

Tabela 1 - Distribuição dos fones consonantais do pomerano

\begin{tabular}{|c|c|c|c|}
\hline Símbolo & Classificação do segmento & Exemplo & Tradução \\
\hline [p] & Oclusiva bilabial surda & ['plats] & Terreiro, pátio \\
\hline$\left[\mathrm{p}^{\mathrm{h}}\right]$ & Oclusiva bilabial surda aspirada & ['p $\left.\mathbf{p}^{\mathrm{h}} \varepsilon p \varepsilon\right]$ & Pimenta \\
\hline$[\mathrm{b}]$ & Oclusiva bilabial sonora & ['blox] & Azul \\
\hline$[\mathrm{t}]$ & Oclusiva alveolar surda & {$[' t a f]$} & Bolsa \\
\hline$\left[\mathrm{t}^{\mathrm{h}}\right]$ & Oclusiva alveolar surda aspirada & {$\left[\mathbf{t}^{\mathrm{h}} \mathrm{i}:\right]$} & Coruja \\
\hline [d] & Oclusiva alveolar sonora & {$[$ 'dax $]$} & Dia \\
\hline$[\mathrm{k}]$ & Oclusiva velar surda & {$[\mathrm{k} э \mathrm{p}]$} & Cabeça \\
\hline$\left[\mathrm{k}^{\mathrm{h}}\right]$ & Oclusiva velar surda aspirada & ['k $\left.\mathbf{k}^{\mathbf{h}} \mathrm{i}: c ̧\right]$ & Igreja \\
\hline$[\mathrm{g}]$ & Oclusiva velar sonora & [gaud] & Bom \\
\hline$[\mathrm{m}]$ & Nasal bilabial & ['mute] & Avó \\
\hline$[\mathrm{n}]$ & Nasal alveolar & ['nyse] & Garrote \\
\hline$[\mathrm{n}]$ & Nasal palatal & ['ẽnəł] & Anjo \\
\hline$[\mathrm{y}]$ & Nasal velar & ['lank] & Comprido \\
\hline$[\mathrm{r}]$ & Tepe alveolar & ['rere] & Falar \\
\hline$\left[\mathrm{t} \int\right]$ & Africada pós-alveolar surda & [utt'rutfe] & Deslizar \\
\hline$[\mathrm{f}]$ & Fricativa labiodental surda & ['fote $]$ & Avô \\
\hline$[\mathrm{v}]$ & Fricativa labiodental sonora & ['vote] & Água \\
\hline$[\mathrm{s}]$ & Fricativa alveolar surda & {$\left[\right.$ su:k $\left.^{\mathrm{h}} \mathrm{e}\right]$} & Açúcar \\
\hline$[\mathrm{z}]$ & Fricativa alveolar sonora & [’zuoiç] & Porca \\
\hline$\left[\int\right]$ & Fricativa pós-alveolar surda & [']ał] & Escola \\
\hline$[\mathrm{ç}]$ & Fricativa palatal surda & [eIç] & Ovo \\
\hline [i] & Fricativa palatal sonora & ['leı̇] & Deitar \\
\hline$[\mathrm{x}]$ & Fricativa velar surda & {$[$ 'dax $]$} & Dia \\
\hline$[\mathrm{\gamma}]$ & Fricativa velar sonora & ['noył] & Prego \\
\hline$[\mathrm{h}]$ & Fricativa glotal surda & ['hoke] & Cabide \\
\hline$[\mathrm{h}]$ & Fricativa glotal sonora & ['lafie] & Rir \\
\hline$[\mathrm{j}]$ & Aproximante palatal & [jak] & Blusa \\
\hline$[1]$ & Lateral alveolar & {$[’ \mathrm{l} \varepsilon f]$} & Vivo \\
\hline$[\nmid]$ & Lateral alveolar velarizada & {$[\mathrm{fut}]$} & Cheio \\
\hline
\end{tabular}


Esses 29 fones consonantais reduzem-se a 19 fonemas consonantais: oclusivas bilabiais $/ \mathrm{p}, \mathrm{b} /$, alveolares $/ \mathrm{t}, \mathrm{d} / \mathrm{e}$ velares $/ \mathrm{k}, \mathrm{g} /$, nasais bilabial $/ \mathrm{m} /$, alveolar $/ \mathrm{n} /$ e palatal $/ \mathrm{n} /$, tepe alveolar $/ \mathrm{r} /$, africada pós-alveolar surda $/ \mathrm{t} \mathrm{f}$, fricativas labiodentais /f, v/, alveolares /s, z/, pós-alveolar surda / / e velar surda $/ \mathrm{x} /$, a aproximante palatal $/ \mathrm{j} / \mathrm{e}$ a aproximante lateral alveolar $/ 1 /$, os quais foram identificados através de pares mínimos e análogos.

\subsection{Distribuição complementar}

Alguns segmentos consonantais estão em distribuição complementar, ou seja, quando dois segmentos ocorrem em ambientes exclusivos e não conseguimos identificar pares mínimos ou análogos, então buscamos caracterizálos como alofones ou variantes de um mesmo fonema (PIKE, 1947). Desse modo, encontramos os seguintes casos de distribuição complementar:

As fricativas glotal $[\mathrm{h}]$, velar $[\mathrm{x}]$ e palatal [ç] surdas são foneticamente semelhantes e ocorrem nos seguintes ambientes:

- a fricativa glotal surda $[\mathrm{h}]$ ocorre no início de palavras: [hous] - calça, [hyt] - hoje, ['hø్ıre] ouvir, escutar;

- a fricativa velar surda [x] ocorre no início de sílabas, como em ['kuxãn] - bolo, e no final de sílabas diante de todas as vogais, exceto diante da vogal alta anterior não arredondada [i], conforme podemos observar nos exemplos a seguir: ['naxt] - noite; ['Slext] - mal, ruim; [lox] - buraco;

- a fricativa palatal surda [ç] ocorre no final de sílabas diante da vogal [i]: ['Jpiç] - saliva, ['horiç] - peludo, ['verniç] - poucos. Então,

$$
/ \mathrm{x} / \longrightarrow\left\{\begin{array}{l}
{[\mathrm{h}] / \#+} \\
{[\mathrm{c}] /\left[{ }^{\mathrm{i}}\right]} \\
{[\mathrm{x}] / \mathrm{NDA}}
\end{array}\right.
$$

Essas consoantes tornam-se vozeadas quando estiverem antes ou depois de consoantes vozeadas. Dessa forma:

- a fricativa glotal sonora [h] ocorre no início de palavras, desde que esteja precedida por outra palavra que possua uma vogal ou consoante vozeada. Ex.: [Suada'hore] - cabelo preto, [kõm'he:] - venha cá;

- a fricativa palatal sonora [j] ocorre no final de sílabas diante da vogal [i] seguida de vogal ou consoante sonora. Ex.: [nij'mõn] - lua nova, ['lerje] - deitar.
- a fricativa velar sonora $[\mathrm{\gamma}]$ ocorre no início e no final de sílabas diante de todas as vogais, exceto diante da vogal alta anterior não arredondada [i], precedida ou seguida de vogal ou consoante sonora. Ex.: ['flyyt], asa; ['zIEye], dizer.

A regra pode ser vista como:

$$
/ \mathrm{x} / \rightarrow\left\{\begin{array}{l}
{[\mathrm{f}] / \# \_\mathrm{C}[+ \text { sonora }]} \\
{[\mathrm{j}] /[\mathrm{i}] \_\mathrm{C}[+ \text { sonora }]} \\
{[\mathrm{\gamma}] / \mathrm{NDA} \_\mathrm{C}[+ \text { sonora }]}
\end{array}\right.
$$

As laterais $[1, \nmid]$ estão em distribuição complementar, uma vez que a lateral [1] ocorre em início de sílaba ([lox] - buraco, [løI] - gente, pessoa , ['laxe] - rir) e a lateral [y] ocorre em final de sílaba ([jeł] - amarelo, ['hı̨łtbe] ajudar, [fał] - cair).

Sendo assim,

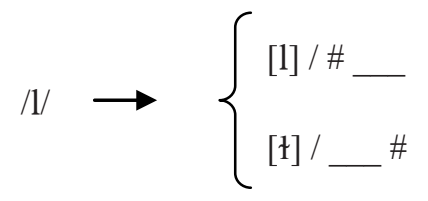

As nasais dental e velar [n, $\mathrm{n}]$, respectivamente, estão em distribuição complementar, uma vez que a nasal velar [n] ocorre em final de sílaba seguida de uma oclusiva velar (['lank] - comprido, ['ãngəł] - anzol) e a nasal dental $[\mathrm{n}]$ ocorre nos demais ambientes ([' $\left.\mathrm{k}^{\mathrm{h}} \mathrm{int}\right]$ criança, [thẽ:n] - dente). Assim:

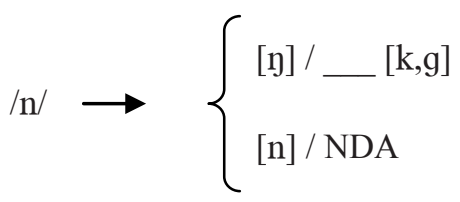

\subsection{Variação livre}

Outros segmentos consonantais estão em variação livre, isto é, a variação dos fones não causa alteração de significado.

As oclusivas bilabial, alveolar e velar surdas [p, t, k] e as oclusivas bilabial, alveolar, velar surdas aspiradas $\left[\mathrm{p}^{\mathrm{h}}, \mathrm{t}^{\mathrm{h}}, \mathrm{k}^{\mathrm{h}}\right]$ podem oscilar em uma mesma palavra ou de falante para falante sem alteração de sentido. Ex.:

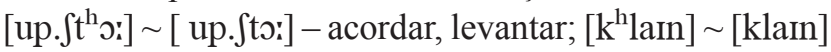
- pequeno; ['p $p^{\mathrm{h} u: s e]} \sim$ ['pu:se] - beijo.

A oclusiva velar sonora [g] e a aproximante velar [j] ocorrem em variação livre no início de algumas palavras. Essas ocorrências devem ser investigadas em pesquisas futuras, uma vez que isso pode ser restrito a alguns itens lexicais somente. Ex.: ['grett] ['jett] - dinheiro; ['gobeł] ['jobeł] - garfo; ['gurk] ['jurk] - pepino;

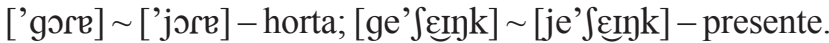




\section{Sistema vocálico do pomerano}

O pomerano possui 23 fones vocálicos, os quais podem ser classificados quanto a altura (baixa, médiabaixa, média-alta e alta), posição do corpo da língua (anterior, central e posterior), arredondamento dos lábios (arredondado e não arredondado) e duração (breve e longa). Na Tab. 2 estão exemplificados os fones vocálicos do pomerano seguidos da classificação articulatória, de exemplos de ocorrência e respectiva tradução em português.

Os fones vocálicos descritos acima resultam em 14 fonemas: as vogais baixas centrais não arredondadas breve e longa /a, a:/, as vogais anteriores média-baixa arredondada breve /œ/, não arredondadas breve e longa $/ \varepsilon$, $\varepsilon: /$, altas arredondadas breve e longa /y, y:/, não arredondadas breve e longa /i, ii/, as posteriores médiobaixas arredondadas breve e longa $/ \mathrm{o}, \mathrm{o}:$, a média-alta arredondada breve $/ \mathrm{o} / \mathrm{e}$ as altas posteriores breve e longa /u, u:/, as quais foram detectadas pela formação de pares mínimos e análogos.

\subsection{Distribuição complementar}

Algumas dessas vogais estão em distribuição complementar:
A vogal média-alta anterior não arredondada breve [e] vem sempre sucedida de [I] ou diante de uma consoante nasal (['ergp ${ }^{\mathrm{h}} \mathrm{I}$ - aipim, ['ẽnet] - anjo), enquanto a vogal $[\varepsilon]$ ocorre nos demais ambientes e quando forma o ditongo [EI] está seguida da vogal [a] ou da fricativa [ç], como em ['treke] - puxar; [meł] - trigo; [1غiç] - oco, vazio; [ręa] - costas). A regra pode ser sistematizada da seguinte forma:

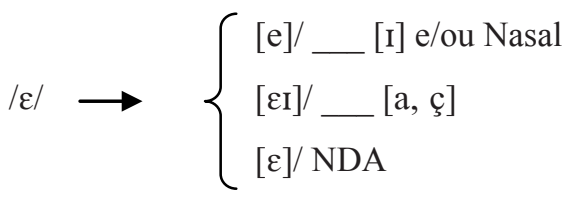

A vogal média-alta anterior arredondada $[\varnothing]$ também ocorre sempre sucedida da semivogal [I] ([brøIç] ponte, [fløia] - pulga, [drøiç] - seco), enquanto a vogal média-baixa anterior arredondada [œ] ocorre nos demais ambientes ([hœł] - inferno; [el'flœxt] - fazer trança; [dœst] - ter sede; [frœm] - estranho, desconhecido). Assim:

$$
/ œ / \rightarrow\left\{\begin{array}{l}
{[ø] /\left[{ }^{[\mathrm{I}]}\right.} \\
{[œ] / \mathrm{NDA}}
\end{array}\right.
$$

Tabela 2 - Distribuição dos fones vocálicos do pomerano

\begin{tabular}{|c|c|c|c|}
\hline Símbolo & Classificação do segmento & Exemplo & Tradução \\
\hline [a] & Vogal baixa central não arredondada breve & [axt] & Oito \\
\hline [a: $]$ & Vogal baixa central não arredondada longa & ['ha:k] & Rastelo \\
\hline$[\mathrm{e}]$ & Vogal baixa central não arredondada breve final & ['kafe] & Café \\
\hline$[œ]$ & Vogal média-baixa anterior arredondada breve & ['hœeł $]$ & Inferno \\
\hline$[œ:]$ & Vogal média-baixa anterior arredondada longa & ['k $\left.\mathrm{k}^{\mathrm{h}} \boldsymbol{e}: \mathrm{nz}\right]$ & Abóbora \\
\hline$[\varepsilon]$ & Vogal média-baixa anterior não arredonda breve & ['ete] & Comer \\
\hline$[\varepsilon:]$ & Vogal média-baixa anterior não arredonda longa & {$[\mathrm{v} \varepsilon \mathrm{i}]$} & Quem \\
\hline [0] & Vogal média-baixa posterior arredondada breve & ['blox] & Azul \\
\hline$[\%:]$ & Vogal média-baixa posterior arredondada longa & {$[\mathrm{d} \mathbf{s}:]$} & Ali \\
\hline$[\varnothing]$ & Vogal média-alta anterior arredondada breve & {$[’ \emptyset \nmid]$} & Óleo \\
\hline$[\varnothing:]$ & Vogal média-alta anterior arredondada longa & ['vø:m] & Verme, larva \\
\hline$[\mathrm{e}]$ & Vogal média-alta anterior não arredondada breve & [eIç] & Ovo \\
\hline$[\mathrm{e}:]$ & Vogal média-alta anterior não arredondada longa & ['pert] & Égua \\
\hline$[\mathrm{o}]$ & Vogal média-alta posterior arredondada breve & ['oust] & Nosso \\
\hline$[\mathrm{O}:]$ & Vogal média-alta posterior arredondada longa & ['oruł] & Coruja \\
\hline$[y]$ & Vogal alta anterior arredondada breve & ['ymfote] & Abraçar \\
\hline$[\mathrm{y}:]$ & Vogal alta anterior arredondada longa & ['dy:ste] & Escuro \\
\hline [i] & Vogal alta anterior não arredondada breve & {$[\mathrm{ik}]$} & $\mathrm{Eu}$ \\
\hline$[\mathrm{I}]$ & Vogal alta anterior não arredondada breve final & {$[\mathrm{er}]$} & Solo \\
\hline$[\mathrm{i}:]$ & Vogal alta anterior não arredondada longa & ['birte] & Morder \\
\hline$[\mathrm{u}]$ & Vogal alta posterior arredondada breve & ['ułt] & Umbigo \\
\hline$[u]$ & Vogal alta posterior arredondada breve final & [suka'rou] & Cana de açúcar \\
\hline$[\mathrm{u}:]$ & Vogal alta posterior arredondada longa & [fuił $]$ & Cheio \\
\hline
\end{tabular}




\subsection{Processo de nasalização}

Nos dados coletados do pomerano não encontramos indícios de que existam vogais nasais e sim processos em que há nasalização da vogal seguida por um elemento nasal consonântico ocorrendo, assim, uma assimilação do traço de nasalidade. $\mathrm{O}$ mesmo ocorre com a língua portuguesa, conforme afirma Mattoso Câmara (2002, p. 59): “A nasalidade pura da vogal não existe, aliás, fonologicamente, porque por meio dela não se cria oposição em português entre vogal pura envolvida de nasalidade e vogal seguida de consoante nasal posvocálica".

$\mathrm{Na}$ língua de imigração pomerana pode haver nasalização ou não diante de um elemento consonântico nasal, conforme podemos observar nos processos a seguir:

A nasalização das vogais não ocorre quando estas estiverem diante da consoante nasal bilabial $[\mathrm{m}]$ em coda simples ou em ditongos [ar] diante de trava silábica nasal. Esse processo refere-se às vogais anteriores e central.

$$
\begin{aligned}
& \text { [im] - abelha } \\
& \text { ['ymfote] - abraçar } \\
& \text { [a:m] - braço } \\
& \text { [va:m] - calor } \\
& \text { ['aIn] - um } \\
& \text { [k'lain] - pequeno }
\end{aligned}
$$

Em contrapartida, as vogais, em geral, assimilam o traço de nasalidade da consoante nasal seguinte, geralmente uma nasal alveolar [n], uma nasal velar [ $\mathrm{n}] \mathrm{e}$ vogais posteriores diante da nasal bilabial [m], tanto em coda simples quanto complexa.

$$
\begin{aligned}
& \text { [sãnt] - areia } \\
& \text { [õ:mz] - de tarde } \\
& \text { ['khãn] - bule } \\
& \text { ['kuxãn] - bolo } \\
& \text { [t'ẽn] - dente } \\
& \text { [Slãy] - cobra }
\end{aligned}
$$

Percebemos, nos casos abaixo, que não houve nasalização das vogais, as quais estão em sílabas diferentes do elemento nasal. Assim, há indícios que a vogal baixa central [a] tônica diante da nasal bilabial [m] precedida do ditongo [aI] não assimila o traço de nasalidade; o mesmo ocorre com os ditongos [er] e [ou] diante da nasal alveolar [n] também em sílaba tônica e, por fim, a vogal média-alta posterior arredondada [o] em sílaba pretônica também não assimila a nasalidade da consoante nasal alveolar [n] seguida do ditongo [ar].

$$
\begin{aligned}
& \text { ['amais] - formiga } \\
& \text { ['veIniç] - poucos } \\
& \text { ['boune] - feijão } \\
& \text { [vo'nar] - quando }
\end{aligned}
$$

Por outro lado, as vogais tornam-se nasalizadas em sílabas diferentes quando não há a presença de ditongos antes ou depois do elemento nasal, seja em sílaba tônica ou átona.

$$
\begin{aligned}
& \text { ['ejeł] - anjo } \\
& \text { ['ẽme] - balde } \\
& \text { ['sine] - cantar } \\
& \text { [k } \mathrm{k}^{\mathrm{h}} \text { õma'se: ] - vem cá } \\
& \text { [fa'briẽne] - queimar } \\
& \text { ['dãme] - tripas }
\end{aligned}
$$

\subsection{Vogais anteriores arredondadas}

O jovem estudado apresenta um processo que pode indicar uma tendência entre os mais jovens ou influência da língua portuguesa, sendo, portanto, outro fato a ser investigado futuramente. As vogais anteriores arredondadas tornam-se não-arredondadas em várias palavras pronunciadas por MFJ. Ex.: [' $\left.\mathrm{k}^{\mathrm{j}} \tilde{\varepsilon} \mathrm{nze}\right] \sim\left[{ }^{\mathrm{K}} \mathrm{k}^{\mathrm{h}} œ n \mathrm{z}\right]$ - abóbora; ['flixte] ['flyxte] - asa; ['fleIde] ['fløide] - assobiar; [tif] [dyf] - bêbado, tonto; [mits] [myts] boné; ['heIre] ['høIre] - escutar.

\section{Estrutura silábica do pomerano}

Segundo Mattoso Câmara (2002), é difícil definir a sílaba do ponto de vista fonético. Segundo ele,

Tem-se partido do efeito auditivo (sílaba sonora), da força expiratória (sílaba dinâmica), do encadeamento articulatório na produção contínua dos sons vocais (sílaba articulatória), da tensão muscular durante essa série de articulações (sílaba intensiva) ou do jogo da musculatura peitoral.

Dessa forma, o autor ressalta o movimento de ascensão que é o ápice da sílaba, o centro silábico, seguido de um movimento decrescente. Assim, a vogal funciona como o centro silábico, pois é o som mais sonoro, possui maior força expiratória, tem articulação mais aberta e tensão muscular mais firme. Entretanto, as consoantes soantes não estão excluídas dessa posição central da sílaba.

A estrutura da sílaba pode ser resumida possuindo um aclive, um centro e um declive, resultando nos seguintes tipos silábicos: sílaba simples, constituída por uma V (vogal); sílaba complexa crescente, CV (consoante e vogal); sílaba complexa crescente-decrescente, como VC. Além disso, há a sílaba aberta ou livre, isto é, não possui um elemento após o núcleo, como em $\mathrm{V}$ e CV; e a sílaba fechada ou travada, a qual possui um elemento após o núcleo, como em VC e CVC (MATTOSO CÂMARA, 2002).

Uma outra forma de descrever a sílaba relaciona-se à teoria métrica da sílaba que foi formulada por Selkirk 
(1982), baseada nas propostas de Pike e Pike (1947) e Fudge (1969), propondo que a sílaba possui um ataque (A), posição ocupada por consoantes, e uma rima (R), a qual consiste em um núcleo $(\mathrm{Nu})$, constituído por vogal, e uma coda (Co), que pode ser preenchida por semivogal ou consoante. $\mathrm{O}$ ataque e a coda podem ser vazios. Tanto o ataque quanto a coda podem ser complexos, quando estes apresentarem mais de um elemento (COLLISCHON, 1999).

Sendo assim, as línguas possuem restrições silábicas específicas em relação a sua estrutura. Segundo Wetzels (1995),

Muitas línguas, por exemplo, colocam restrições específicas quanto à quantidade de posições segmentais que podem ser preenchidas na rima silábica (núcleo + coda), no onset ou na coda. Da mesma forma, podem existir limitações referentes à natureza dos segmentos possíveis de ocorrer no onset, no núcleo ou na coda.

\subsection{Descrição dos tipos silábicos do pomerano}

As estruturas silábicas do pomerano podem ser definidas em dezenove tipos, em que a menor estrutura abrange somente uma vogal (V) e as mais complexas possuem tanto o ataque quanto a coda complexas (CCVGCC) ou um ataque complexo com três elementos consonantais (CCCVG). Dessa forma, esses padrões podem ser resumidos pelo padrão geral: $(C)(C)(C) \mathrm{V}$ (G) (C) (C), o que significa que os ataques e as codas são facultativos. Abaixo, apresentamos alguns exemplos dos tipos silábicos encontrados no corpus recolhido:

- V: ['e.tø], comer; ['ẽ.me], balde; ['u.ne], embaixo; ['a.mars], formiga.

- VG: [eI], terra; [ü.ve], barranco; [el. $\mathrm{p}^{\mathrm{h}} \mathrm{I}$ ], aipim.

- CV: [do], ali; [nu:], agora; [go], andar; ['vo.te], água.

- VC: [a:m], braço; [im], abelha; [ym.fo.te], abraçar; ['am.bi.ne], amarrar.

- VCC: [ẽnt], pato; [õmz], à tarde; [عdn], alimento; [عzł], burro.

- VGCC: [oust], nosso; [arst], primeiro.

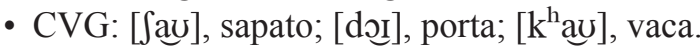

- CVC: [dum], bobo; [taS], bolsa; [lox], buraco; [tas], xícara.

- CVGC: [lęx], vazio; [touf], pomba.

- CVCC: [runt], redondo; [zułt], sal; [hats], garganta; $\left[\mathrm{k}^{\mathrm{h}} \varepsilon \mathrm{d} \mathrm{t}\right]$, panela.

- CGVCC: [licts], último; [bưst], peito; [mIEtk], leite;

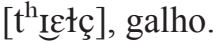

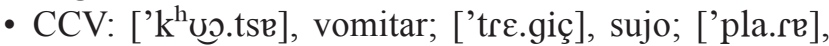
miado.

- CCVG: ['grou.de], grande; [Star], pedra; ['brau.re], irmão; ['flø].te], assobiar.
- CCVC: [klək], relógio; [flus], rio; [k ${ }^{\mathrm{h}}$ rik], rodo; [ftof], poeira; [Spiç], saliva.

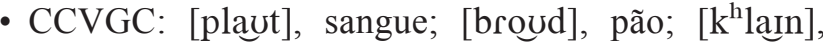
pequeno.

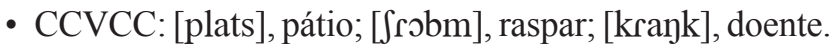

- CCVGCC: [hi.'dręınk], bebida alcoólica.

- CCCVC: [Strop], caminho.

- CCCVG: ['Strou.zet], colchão.

O sistema fonológico dessa língua de imigração impõe algumas restrições quanto a constituição das sílabas:

a) O núcleo da sílaba será sempre constituído pelas vogais /a, a: œ, $\varepsilon, \varepsilon:$, , o: o, y, y: i, i: u, u:/, conforme os exemplos: ['a.mars], formiga; [a:m], braço; ['k $\mathrm{k}^{\mathrm{h}}$ ẽnz], abóbora; ['ع.te], comer; [fєæ:1], muito; [klok], relógio; [jo:], ano; [koł], repolho; [myts], boné; [sy:n], pecado; [dik], gordo; [bi:te], morder; [fuł], podre; e [fu:ł], cheio.

b) A primeira posição do ataque silábico é constituída pelas consoantes $/ \mathrm{p}, \mathrm{b}, \mathrm{t}, \mathrm{d}, \mathrm{k}, \mathrm{g}, \mathrm{f}, \mathrm{v}, \mathrm{s}, \mathrm{z}, \mathrm{\int}, \mathrm{x}$, $\mathrm{t} \int, \mathrm{r}, \mathrm{m}, \mathrm{n}, \mathrm{n}, \mathrm{l}, \mathrm{j} / \mathrm{\text {: }}$ ['pūx], sapo; [bűst], peito;

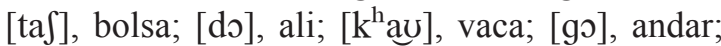
['fote], avô; ['vo.te], água; ['site], sentar; [zułt], sal; [Sau], sapato; ['hoke], cabide; [utt'rutfe], deslizar; [runt], redondo; [mıєtk], leite; [nu:], agora; ['enəł], anjo; [lıcts], último; [jo], sim.

c) $\mathrm{O}$ ataque complexo com dois elementos consonantais é ocupado pelas consoantes oclusivas $/ \mathrm{p}, \mathrm{b}, \mathrm{t}, \mathrm{d}, \mathrm{k}, \mathrm{g} / \mathrm{e}$ pelas fricativas /f, $\mathrm{J} / \mathrm{em}$ primeira posição, conforme podemos observar nos exemplos: ['pla.re], miado; ['brau.re], irmão; ['tre.giç], sujo; [hi.'drє̧ık], bebida alcoólica; [klək], relógio; ['grou.de], grande; ['fløु.te], assobiar; e [Stof], poeira. As restrições para a combinação das consoantes do ataque complexo serão descritas adiante.

d) $\mathrm{O}$ ataque complexo com três consoantes será sempre constituído pela fricativa pós-alveolar surda /S/ em posição inicial, conforme [Strop], caminho, e [']trou.zet], colchão.

e) Em coda simples (como CVC, VC) ocorrem as oclusivas /p, b, t, d, k, g/, as fricativas /f, v, s, $\mathrm{z}, \int, \mathrm{x} /$, a africada $/ \mathrm{t} \mathrm{f} /$, as nasais $/ \mathrm{m}, \mathrm{n} / \mathrm{e}$ a lateral /1/: [op], macaco; [lu:b], janela de madeira; [plaust], sangue; [broud], pão; [k $\mathrm{k}^{\mathrm{h}} \mathrm{ik}$ ], rodo; [u:g], estômago; [touf], pomba; [ $\left.\int \mathrm{ruv}\right]$, parafuso; [tas], xícara; [õmz], escuro; [ta $]$, bolsa; [lox], buraco;

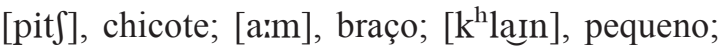
[fu:ł], cheio.

d) Em coda complexa (por exemplo, CVCC) ocorrem as oclusivas $/ \mathrm{t}, \mathrm{d}, \mathrm{k} /$, as fricativas $/ \mathrm{s}, \mathrm{z}, \mathrm{x} /$, as nasais $/ \mathrm{m}, \mathrm{n} / \mathrm{e}$ a lateral $/ 1 /$, conforme os exemplos: [ẽnt], 
pato; [hãnd], mão; [mIEłk], leite; [hałs], garganta;

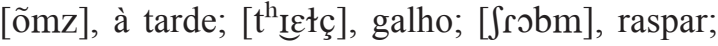
[عdn], alimento; e [عzł], burro. As restrições de combinação dos elementos consonantais em coda complexa serão descritas posteriormente.

Pelo esquema arbóreo, podemos visualizar de forma mais precisa os princípios acima representados. Vale ressaltar que a combinação dos elementos consonantais presente nas posições de ataque e coda complexos será descrita logo abaixo da figura.

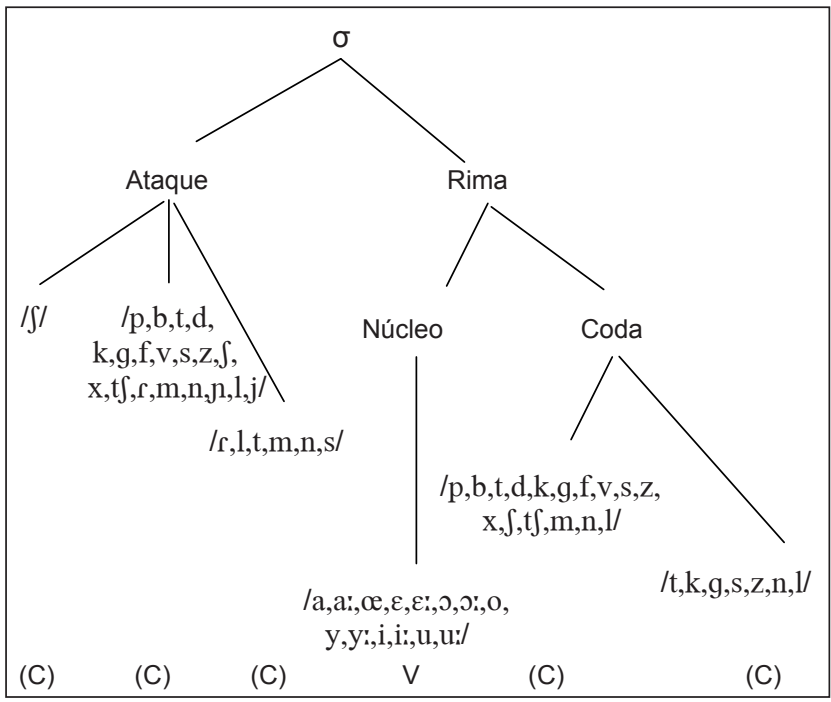

Figura 1 - Esquema arbóreo da estrutura silábica do pomerano

Esses padrões silábicos apresentam restrições particulares. O padrão $\mathrm{V}$ será sempre constituído por vogais /a, a:, œ, $\varepsilon, \varepsilon:$, o, o:, o, y, y:, i, i:, u, u:/ e o padrão $\mathrm{VG}$, pelas vogais seguidas pelos glides /I, $\mathrm{U} /$.

O padrão $\mathrm{CV}(\mathrm{G})$ é constituído pelas consoantes

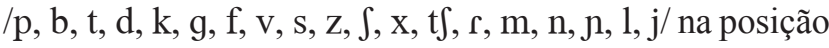
do ataque e pelas vogais no núcleo.

A sílaba CCV é formada pelas consoantes $/ b$, $t$, $\mathrm{d}, \mathrm{k}, \mathrm{g}, \mathrm{f}, \mathrm{s} / \mathrm{em}$ primeira posição e o tepe alveolar $/ \mathrm{f} /$ em segunda posição como em ['bro.re], assar; [trext], pronto; [drøI], seco; ['kri.ve.li], pensar; [gras], capim; [frux], mulher; [ $\left.\int r u v\right]$, parafuso. A lateral aproximante /1/ em segunda posição combina-se com /p, b, k, g, f, s/ em primeira posição: [plats], pátio; [blox], azul; [klain], pequeno; [glat], liso; [flar $\left.\int\right]$, carne, [Slo:], bater. Há, ainda, a combinação da fricativa pós-alveolar surda $/ \mathrm{S} / \mathrm{com}$ a oclusiva alveolar surda /t/, com a nasal bilabial $/ \mathrm{m} / \mathrm{e}$ com a nasal alveolar /n/: [up.'Sto:], levantar; [Stau], cadeira;

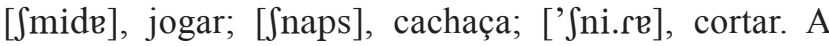
oclusiva velar surda $/ \mathrm{k} /$ combina-se com a nasal alveolar /n/ e com a fricativa alveolar surda /s/: ['kno.ge], joelho; [ع:ks], machado. Por fim, a oclusiva bilabial surda /p/ combina-se com a fricativa alveolar surda /s/, como em ['Su.pse], empurrar.

$\mathrm{O}$ ataque complexo com três elementos consonantais $(\mathrm{CCCV}(\mathrm{G}))$ é constituído pela fricativa pós-alveolar surda /S/ em primeira posição, pela oclusiva alveolar surda /t/ em segunda posição e pelo tepe alveolar / $/$ em terceira posição, conforme podemos observar nos exemplos: [Strop], caminho; ['Strou.zak], colchão.

A coda simples em que há um elemento consonantal após o núcleo ou glide $(\mathrm{V}(\mathrm{G}) \mathrm{C})$ é constituída pelos fonemas

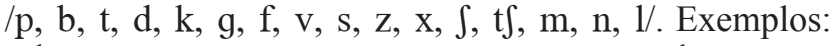

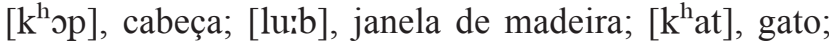
[groud], grande; [buk], barriga; [dicg], cobertor; [lef], vivo; [ $\left.\int \mathrm{ruv}\right]$, parafuso; [nes], nariz; ['je:zuz], Jesus; [blox], azul; [erç], ovo; [taf], bolsa; [pitf], chicote; [blam], flor; [klain], pequeno; [Sirł], casca.

O tipo silábico VCC que forma a coda complexa constitui-se da combinação dos seguintes fonemas consonantais: oclusiva bilabial surda e fricativa alveolar surda /ps/ ([Snaps], cachaça), oclusiva alveolar surda e fricativa alveolar surda /ts/ ([pits], pouco), oclusiva alveolar sonora e nasal alveolar /dn/ ([عdn], alimento), oclusiva alveolar sonora e lateral aproximante alveolar /dl/ (['p $\left.{ }^{\mathrm{h}} \mathrm{I} \mathrm{d} \mathrm{d}\right]$, galinha d'angola), oclusiva velar surda e fricativa alveolar surda $/ \mathrm{ks} /$ ([عks], machado), fricativa alveolar surda e oclusiva alveolar surda /st/ ([nIEst], choca); fricativa alveolar sonora e lateral aproximante alveolar /zl/ ([ع:zł], burro), fricativa labiodental surda e oclusiva alveolar surda /ft/ ([hyft], veneno), fricativa velar surda e oclusiva alveolar surda /xt/ ([trext], pronto), fricativa velar surda e aproximante lateral alveolar /xl/ ([n๖xł], prego), nasal bilabial e fricativa alveolar sonora $/ \mathrm{mz} /$ ([õmz], escuro), nasal alveolar e oclusiva alveolar surda /nt/ ([sãnt], areia), nasal velar e as oclusivas velares [yk, yg] ([bẽınk], banco de sentar; [Slãng], cobra), tepe alveolar e oclusiva velar surda/rk/ ([jurk], pepino) e, por fim, a lateral aproximante seguida de oclusiva alveolar surda ou oclusiva velar surda ou fricativa alveolar surda /lt, lk, ls/, como em [kutt], frio; [mıtkk], leite e [hats], pescoço, respectivamente.

\section{Conclusão}

Este artigo teve como objetivo descrever, de forma breve, o sistema fonético e fonológico da língua de imigração pomerana recorrendo aos pressupostos teóricos da fonêmica, proposta por Pike (1947). Contudo, ainda há muitas questões a serem resolvidas no que se refere à organização do sistema sonoro dessa língua tendo em vista a complexidade da mesma, o que será feito em pesquisas futuras.

Conforme vimos, os dados linguísticos que formaram o corpus dessa pesquisa foram obtidos junto a falantes de 
pomerano (bilíngues e uma monolíngue) residentes no município de Santa Leopoldina, ES. A coleta do corpus ocorreu em duas etapas: a primeira com uma lista de 600 palavras junto com os três falantes bilíngues, mas foi insuficiente para a descrição fonológica, sendo necessário fazer uma nova lista de 190 palavras e mais uma coleta, dessa vez com a falante monolíngue e uma bilíngue, o que possibilitou confirmar alguns dados e completar a descrição fonológica.

O inventário fonético é composto por 29 fones consonantais e 23 fones vocálicos. A partir da formação de pares mínimos e análogos chegamos a 19 fonemas consonantais e 14 fonemas vocálicos.

A estrutura silábica do pomerano é formada por 19 tipos diferentes de sílabas organizadas por ataque e coda simples e complexo. Percebemos que há dois ataques complexos formados com três consoantes, sendo a primeira sempre uma fricativa alveopalatal surda [S].

Para uma descrição mais completa do pomerano ainda é preciso pesquisar o acento e o ritmo dessa língua de imigração. Enfim, há muito trabalho a ser realizado.

Diante de tudo isso, esperamos que este trabalho contribua para o conhecimento da organização sonora de uma língua ainda muito falada em alguns municípios capixabas, em algumas regiões de Minas Gerais, de Rondônia, do Rio Grande do Sul e de Santa Catarina.

\section{Referências}

BAHIA, Joana. A "lei da vida": confirmação, evasão escolar e reinvenção da identidade entre os pomeranos. Educação $e$ Pesquisa (USP), São Paulo, v. 27, 2006, p. 01-198. Disponível em: <http://www.scielo.br/pdf/ep/v27n1/a05v27n1.pdf >. Acesso em: 13 jan. 2011.

BANDEIRA, Marta Helena Tressmann. Diferenças entre crianças monolíngues e multilíngues no desempenho de tarefas de funções executivas e na transferência de padrões de VOT (Voice Onset Time) entre as plosivas surdas do pomerano, do português e do inglês. Dissertação (Mestrado em Letras) Programa de Pós-Graduação em Letras, Universidade Católica de Pelotas, Pelotas, 2010

BENINCÁ, Ludimilla Rupf. Dificuldade no domínio de fonemas do português por crianças bilíngues de português e pomerano. Dissertação (Mestrado em Estudos Linguísticos) - Programa de Pós-Graduação Stricto Sensu em Estudos linguísticos, Universidade Federal do Espírito Santo, Vitória, 2008.

COLLISCHON, Gisela. A sílaba em português. In: BISOL, Leda (Org.). Introdução a estudos de fonologia do português brasileiro. 2. ed. Porto Alegre: EDIPUCRS, 1999. p. 91-123.
HAESE, Aline. A influência do pomerano no aprendizado de Língua Portuguesa. In: ABRALIN EM CENA ESPÍRITO SANTO, 2009, Vitória. Anais... Vitória. CD-ROOM, 2009. p. 01-08.

MATTOSO CÂMARA JR, Joaquim. Estrutura da Língua Portuguesa. 35. ed. Petrópolis: Vozes, 2002.

PIKE, Kenneth Lee. Phonemics: a technique for reducing languages to writing. Ann Arbor: The University of Michigan Press, 1947.

SALAMONI, Giancarla. A imigração alemã no Rio Grande do Sul - o caso da comunidade pomerana de Pelotas. História em Revista (UFPel), v. 07, 2001, p. 25-42. Disponível em: $<$ http://www.ufpel.tche.br/ich/ndh/downloads/historia em revista_07_Giancarla_Salamoni.pdf $>$. Acesso em: 13 jan. 2011.

SCHAEFFER, Shirlei Conceição Barth; MEIRELES, Alexsandro Rodrigues. Padrões de vozeamento de consoantes plosivas em falantes de pomerano (L1) e de português (L2). In: CONGRESSO INTERNACIONAL DA ABRALIN, VII, 2011, Curitiba. Anais..., Curitiba, 2011. p. 4009-4021. (CD-room ISSN 2179-7145).

SCHAEFFER, Shirlei Conceição Barth. Interferências da oralidade na escrita de alunos descendentes de pomeranos do ensino fundamental. Monografia (Especialização em Estudos da Linguagem) - Faculdade Saberes, Vitória, 2010.

TRESSMANN, Ismael. O pomerano: uma língua baixosaxônica. In: Educação, Cultura e Sociedade-Revista da Farese (Faculdade da Região Serrana), Santa Maria de Jetibá, v. 1, p. 10-21, 2008. ISSN: 21765251.

TRESSMANN, Ismael. Dicionário enciclopédico: Pomerano e Português. Santa Maria de Jetibá, 2006.

TRESSMANN, Ismael. Da sala de estar à sala de baile: estudo etnolinguístico de comunidades camponesas pomeranas do estado do Espírito Santo. Tese (Doutorado) - Rio de Janeiro, 2005.

TRESSMANN, Ismael. Bilingüismo no Brasil: O caso da Comunidade Pomerana de Laranja da Terra. Associação de Estudos da Linguagem (ASSEL-Rio), Universidade Federal do Rio de Janeiro - UFRJ, Rio de Janeiro, 1998.

ZIMMER, Márcia; BANDEIRA, Marta; BLANK, Cíntia Avila. A dinâmica do multilinguismo na transferência de padrões de aspiração de obstruintes iniciais entre o pomerano (L1), o português (L2) e o inglês (L3). In: BORBA, Valquíria; CARVALHO, Maria Leônia Garcia Costa; LIMA, Geralda Oliveira Santos (Org.). Contribuições para a pesquisa em linguística nas diferentes áreas: partilhando reflexões e resultados. Maceió: EDUFAL, 2009. p. 57-72.

WETZELS, Leo (Org.). Estudos fonológicos das línguas indígenas brasileiras. Rio de Janeiro: Editora UFRJ, 1995.

Recebido: 28 de agosto de 2013

Aprovado: 21 de dezembro de 2013

Contato: shirleischaeffer@yahoo.com.br; meirelesalex@gmail.com 